American Journal of Pharmaceutical Education 2021; 85 (3) Article 8428.

\title{
COMMENTARY
}

\section{Equity for and Inclusion of Non-Tenure-Track Pharmacy Faculty Within Academia}

\author{
Brian L. Erstad, PharmD, ${ }^{\mathrm{a}}$ Andrea Romero, PhD, ${ }^{\mathrm{b}}$ Robert Miller, MA, ${ }^{\mathrm{c}}$ Carl Liaupsin, EdD, ${ }^{\mathrm{d}}$ \\ Ole J. Thienhaus, MD, MBA, ${ }^{\mathrm{e}}$ Paul Wagner, MS, MBA, ${ }^{\mathrm{f}}$ Edella Schlager, $\mathrm{PhD},{ }^{\mathrm{g}}$ Gayle A. Brazeau, $\mathrm{PhD}^{\mathrm{h}, \mathrm{i}}$ \\ ${ }^{a}$ University of Arizona, College of Pharmacy, Tucson, Arizona \\ ${ }^{\mathrm{b}}$ University of Arizona, College of Agriculture and Life Sciences, Tucson, Arizona \\ ${ }^{\mathrm{c}}$ University of Arizona, School of Architecture, Tucson, Arizona \\ ${ }^{\mathrm{d}}$ University of Arizona, College of Education, Tucson, Arizona \\ ${ }^{\mathrm{e}}$ University of Arizona, College of Medicine, Tucson, Arizona \\ ${ }^{\mathrm{f}}$ University of Arizona, College of Applied Science and Technology, Tucson, Arizona \\ ${ }^{\mathrm{g}}$ University of Arizona, School of Government and Public Policy, Tucson, Arizona \\ ${ }^{\mathrm{h}}$ Marshall University, School of Pharmacy, Huntington, West Virginia \\ ${ }^{\mathrm{i}}$ Editor, American Journal of Pharmaceutical Education, Arlington, Virginia
}

Submitted October 16, 2020; accepted November 23, 2020; published March 2021.

\begin{abstract}
Although there are at least twice as many non-tenure-track first-time pharmacy faculty as tenured and tenure-track first-time pharmacy faculty entering academia based on data collected from 2013 to 2019, there are ongoing equity, inclusion, and advancement issues between these categories of faculty that require consideration. Contracts with clear descriptions of responsibilities are needed along with regular evaluations and promotion opportunities based on the faculty member's performance of the assigned responsibilities, appropriate compensation including fringe benefits, inclusion in institutional voting and governance, and due process protections against abrupt termination. Further, universities and schools and colleges of pharmacy should foster a culture that values all faculty regardless of rank or position. The purpose of this commentary is to describe ongoing efforts and lessons learned by one public university with a college of pharmacy that has non-tenure-track and tenure-track faculty. Our hope is to provide insight into how these experiences could be used as a basis to inform changes in policy by other universities with a school or college of pharmacy, as well as to inform possible changes to the Academy's policies.
\end{abstract}

Keywords: academia, academic performance, clinical, university

\section{INTRODUCTION}

The American Association of University Professors (AAUP) uses the term contingent faculty to refer to faculty positions other than tenure-track that often have little job security or diminished protections for academic freedom. ${ }^{1}$ Contingent positions are appealing from an institutional standpoint as they allow more flexibility in hiring and retention. Accordingly, AAUP lists a variety of potential faculty positions as contingent, including nontenure-track faculty, clinical faculty, lecturers, instructors, teaching assistants, postdoctoral researchers, adjunct faculty, and part-time faculty. In the academic pharmacy literature, discussions pertaining to faculty positions are

Corresponding Author: Brian L. Erstad, University of Arizona, College of Pharmacy, 1295 N. Martin Ave., Tucson, AZ 85721. Tel: 520-626-4289. Email: erstad@pharmacy. arizona.edu usually of a more dichotomous nature as there are approximately twice as many first-time non-tenure-track faculty as tenured and tenure-track faculty entering academia based on data collected from 2013 to 2019., ${ }^{2,3}$ Most of these non-tenure-track faculty members are clinical. Additionally, much of the academic pharmacy literature pertaining specifically to clinical practice faculty is focused on scholarship, which is not surprising as practice faculty are frequently expected to perform scholarly activities but often have little formal training in this area. ${ }^{4-7}$ The requirement for practice faculty members to perform scholarship in addition to their teaching, service, and clinical practice responsibilities leads to higher rates of burnout in this group compared to rates among tenuretrack faculty members. ${ }^{8,9}$ There is much less in the pharmacy literature on general equity, inclusion, and advancement issues for non-tenure-track appointments, ranging from promotion opportunities to participation in 


\section{American Journal of Pharmaceutical Education 2021; 85 (3) Article 8428.}

unit and college governance. In this commentary we describe some of the major initiatives related to non-tenuretrack and tenure-track equity, inclusion, and advancement issues at a public, research 1 university that has a college of pharmacy with clinical practice faculty members. Our hope is to provide insights that can serve as the basis for changes in academic policies for other universities with schools or colleges of pharmacy that are contemplating similar initiatives, as well as the basis for changes in Academy policy.

In June 1993, AAUP released a report titled "The Status of Non-Tenure-Track Faculty," which was adopted by elected council leadership. ${ }^{10}$ Prior to listing a series of recommendations pertaining to non-tenure-track faculty, the preface of the report raised concerns about administrative attempts to move faculty off the tenure-track and issue term-limited contracts to full-time non-tenure-track faculty that would, among other things, affect the quality of education and undermine the stability of the tenure system. The report recommended that schools limit their reliance on non-tenure-track faculty and use of part-time faculty so that these faculty members provide no more than $15 \%$ of the total instruction delivered by the institution. The report listed eight recommendations as minimum standards for non-tenure-track faculty: description of duties, regular evaluations, compensation and promotion based on performance of specified duties, appropriate compensation and fringe benefits, timely notice of nonreappointment, sufficient time and conditions necessary to perform assigned professional duties, inclusion in institutional and departmental governance, and appropriate consideration of part-time faculty for full-time positions that become available. Following publication of the AAUP report, other publications on the AAUP website discussed the rights of non-tenure-track faculty and attempts to control the increasing numbers of non-tenure-track faculty holding contingent appointments. ${ }^{11-13}$ In November 2012, AAUP council leadership adopted a policy on inclusive governance for faculty members with contingent appointments, which are estimated to comprise over $75 \%$ of all US faculty appointments (up from approximately 55\% in 1975). ${ }^{14}$ The five principles forming the basis of recommendations in this report were as follows: the term "faculty" should be defined on an inclusive rather than exclusive basis, faculty in contingent appointments should have opportunities for governance similar to those in tenure-track appointments, governance opportunities must be practiced, academic freedom and governance reinforce each other, and all faculty members should have academic freedom and be entitled to due process protections.

With respect to pharmacy schools, the substantial increase in the proportion of clinical (usually non-tenure- track) to tenure-track faculty over the past several decades reflects an attempt to improve the foundational practice skills of pharmacy students prior to graduation. ${ }^{3}$ In contrast to tenure-track faculty with teaching and research responsibilities centered on more fundamental scientific research, it is not uncommon for clinical faculty members to have at least $25 \%$ of their total effort focused on activities at a clinical practice site. The increased percentage of clinical activities necessitates a reduction in some other area of effort, which is usually scholarship. These changes come at a time when the tenure system is under increasing scrutiny regarding long-term faculty productivity, inconsistent and unfair application of tenure-related policies and procedures, and diversity and inclusion issues. ${ }^{15}$ There has been a paucity of discussion of these issues in the academic pharmacy literature and a lack of guidance on them from the Academy despite the substantial changes in the composition of pharmacy faculty in the past few decades and the increasing scrutiny of tenured positions. For example, AACP does not have a formal policy regarding equity, inclusion, and advancement issues for non-tenure-track vs tenured and tenure-eligible faculty members. ${ }^{16}$ Similarly, there is no mention of this issue in AACP's current strategic plan. ${ }^{17}$

\section{DISCUSSION}

\section{Initiatives at the University of Arizona}

The University of Arizona launched initiatives related to recruitment, promotion, and retention in support of career-track faculty. These initiatives promote the university's goals and philosophic underpinnings for creating equitable and inclusive conditions of employment for all faculty. One of the early initiatives concerns a list of best practices developed by a university task force with the intent of providing guidance to departments and colleges beyond minimum standards for non-tenure-track faculty, such as those compiled by AAUP. These initiatives are a work in progress. Principles of equity and inclusion involve cultural changes that must be desired and adopted system-wide, with ongoing assessments of effectiveness.

Changes in leadership at the University of Arizona in 2019 gave impetus to the new initiatives for non-tenuretrack faculty. One of the early initiatives was a change in track title from non-tenure-track to career-track faculty to be inclusive (ie, what they are) rather than exclusive (ie, what they are not). This change was made as a result of a larger discussion of titles that included those for faculty in adjunct positions. Revised promotion and tenure documents at the university level addressed the specifics of career-track faculty. For example, in the summary of the candidate's workload assignment, categories were added for clinical service, extension, and other professional 


\section{American Journal of Pharmaceutical Education 2021; 85 (3) Article 8428.}

activities. Another change to the promotion and tenure documents for career-track faculty was a revision of the template letter to external reviewers that included consideration of teaching and service in addition to the previous focus on scholarship. In the same spirit, mandates for revised promotion and tenure documents in departments and colleges were developed and implemented. Similarly, modifications were made to the policy and process for annual performance reviews that enabled the university to use the same basic review process for careertrack, tenured, and tenure-eligible faculty. Examples include requirements for peer review at the department, college, and university levels. Directions were also provided for subsequent meetings between the administrative head and the faculty member to discuss the findings of the review.

An ad hoc committee of the University of Arizona Faculty Senate (voting members include administrators, faculty, students, and appointed personnel) has an ongoing charge to identify opportunities for professional advancement and full participation in shared governance at all levels of the University for career-track faculty. Among their findings, this committee reported that large number of current titles has made it difficult for careertrack faculty to understand what processes (eg, promotion ladders) and what rights (eg, participation in shared governance) apply to their specific titles. The university's vice provost also appointed two task forces: the first was charged with evaluating annual performance review procedures (still ongoing) for career-track faculty and the second was charged with developing best practices for faculty with career-track appointments (Table 1).
The Career-track Faculty Task Force, which was comprised of volunteers from among department chairs and center directors, developed a list of best practices for career-track faculty at the University of Arizona. This task force was led by the head of the Department of Pharmacy Practice \& Science. Other task force members included interdisciplinary faculty from the Honors College, Architecture, Applied Technology, Linguistics, Disability and Psychoeducational Studies, Physics, Psychiatry, and the School of Government and Public Policy. Issues were initially discussed by in-person meetings and then transitioned to virtual meetings and email communications because of COVID-19. The task force employed an iterative (modified Delphi approach) for decisionmaking. Ultimately there was unanimous support for six best practices, which underwent minor modifications by a University Steering Committee on Career-track Faculty Processes with subsequent distribution to all department heads and directors for feedback (Table 1).

The Provost also appointed the Steering Committee on Career-track Faculty Processes, with representation from the Department of Human Resources, University Analytics and Institutional Research, the faculty senate, department chairs, and the provost's office. The committee's charge was to identify and advance changes to university policy and administrative processes to improve recruitment, promotion, and retention in support of career-track faculty with the goal of creating equitable and inclusive conditions of employment for all faculty at the university. The work of the steering committee is an ongoing effort that is taking place in three phases beginning with shared governance issues, followed by potential

Table 1. Best Practices for Faculty with Career-Track Appointments as Identified by a Career-Track Faculty Task Force

\begin{tabular}{|c|c|}
\hline $\begin{array}{l}\text { Voting and } \\
\text { governance }\end{array}$ & $\begin{array}{l}\text { Career-track faculty should have the same rights to vote and participate in unit governance as tenure } \\
\text { track/tenured faculty, except as limited by University Handbook for Appointed Personnel (UHAP) policy. }\end{array}$ \\
\hline $\begin{array}{l}\text { Contracts, equity } \\
\text { and compensation }\end{array}$ & $\begin{array}{l}\text { Career-track faculty should have the opportunity for multi-year contracts to the degree that that college } \\
\text { and institutional finances permit, as well as clear and non-cumbersome mechanisms for career } \\
\text { advancement and compensation commensurate with their contributions to the institution and } \\
\text { individual qualifications. }\end{array}$ \\
\hline $\begin{array}{l}\text { Definitions, titles } \\
\text { and percent } \\
\text { effort }\end{array}$ & $\begin{array}{l}\text { The broader title of career track should be adopted for all non-adjunct, non-visiting faculty who are not } \\
\text { classified as tenured, tenure-eligible, or continuing status. All references to non-tenure track should be } \\
\text { eliminated. }\end{array}$ \\
\hline $\begin{array}{l}\text { Annual performance } \\
\text { reviews }\end{array}$ & $\begin{array}{l}\text { Career-track faculty should receive annual performance reviews using the same administrative } \\
\text { procedures as tenured, tenure-eligible, or continuing status faculty. Where appropriate and needed, } \\
\text { specific review criteria should be developed in service to these evaluations. }\end{array}$ \\
\hline Promotion & $\begin{array}{l}\text { A clear distribution of effort should be assigned upon hire and revisited annually. Decisions on } \\
\text { promotion should be based on performance in workload assignments by domain (teaching, research, } \\
\text { outreach/service, clinical, etc). }\end{array}$ \\
\hline
\end{tabular}




\section{American Journal of Pharmaceutical Education 2021; 85 (3) Article 8428.}

policy and title changes, and ending with an implementation phase. The hope is to enter the implementation phase of the committee's efforts by the end of 2021.

The issue of faculty titles is particularly challenging given the series of titles allowed by the Arizona Board of Regents (ABOR) and the variety of other titles, often with additional prefixes or suffixes assigned at the departmental and college levels. For example, within the general career-track category, the university allows for other titles such as instructor, lecturer, professor of practice, clinical, research, or just career-track. From the standpoint of the Steering Committee on Career-track Faculty Processes, the University should have a limited number of uniform titles that are mutually exclusive and unambiguous, and are consistent with ABOR policy.

\section{College of Pharmacy Initiatives and Actions}

Apart from efforts at the university level, the College of Pharmacy at the University of Arizona has a long history of working to ensure equity between tenure and nontenure-track faculty with respect to governance, titles, and cultural issues. The college has two departments, the Department of Pharmacology and Toxicology, which has tenure-track and tenured faculty who teach and perform scholarship in pharmacology, toxicology, pharmaceutics, drug delivery, medicinal chemistry, and drug discovery, and the Department of Pharmacy Practice and Science, which has clinical (primarily non-tenure-track), nonclinical-teaching faculty (non-tenure-track), pharmacogenomic (tenure-track), and health and pharmaceutical outcomes' faculty (non-tenure-track, tenured, and tenureeligible). All full-time ( 0.51 or greater full-time equivalent) faculty with responsibilities related to teaching, scholarship, and service (regardless of career- or tenuretrack) have voting privileges on departmental and college issues. Further, all major college committees established by bylaws include faculty from both departments. Another example relates to the term "clinical," which was used in the past as a prefix to the formal titles of assistant, associate, and full professor when describing clinical practice faculty. Approximately 10 years ago, the faculty voted to eliminate the "clinical" prefix for general voting and governance issues to eliminate any possible perception of second-class faculty status in the college. From the standpoint of culture, there is nothing to indicate anything but shared respect between faculty members, regardless of department, tenure status, or academic titles.

\section{Lessons Learned and Future Directions}

Across the Academy there is increasing recognition that issues of equity, inclusion, and advancement exist between non-tenure-track and tenured and tenure-track faculty. Even the term non-tenure-track refers to what faculty members are not rather than what they are or can contribute to the program. For some professional schools (eg, medical schools) where tenure-track faculty may be a small minority, such a negative definition is especially incongruous and inconsistent with promoting a culture of inclusion. There are ongoing efforts by national academic organizations, such as the American Association of University Professors (AAUP), and by universities, such as the University of Arizona, to ensure inclusivity of all faculty members. To achieve this goal, cultural changes will have to be inculcated throughout universities, from appointing career-track faculty to important leadership positions, participating in peer-review committees, providing voting privileges, and, in short, fully incorporating them into the daily life of units or programs. At the same time, they need a functional reason to hold an appointment that is different in nature from their tenured and tenure-eligible colleagues. Recognizing the central and growing roles played by contingent faculty at most universities requires putting policies and practices in place to promote a cohesive culture where all faculty members function as a single equitable community. Failure to promote cohesion is likely to impede timely and effective governance activities necessary to advance the mission of the university.

\section{CONCLUSION}

The experience of one public research university that has a college of pharmacy with clinical practice faculty provides some potential lessons learned and key steps for other colleges or schools contemplating discussions of faculty equity, inclusion, and advancement. Arguably, the most important lesson learned is that major change requires active and visible support by university administrators, such as the provost and vice-provost. While there are changes that can take place at the college or school of pharmacy level, particularly with respect to culture, more encompassing and longer-lasting policy changes are likely to require commitment by university administrators, interconnected university-wide committees, and a variety of stakeholders. Examples would include policy changes related to shared governance, titles, promotion and tenure procedures, and annual performance reviews. Such changes are likely to take time because they often require review and approval by a variety of governing bodies. During the early stages of discussions of faculty equity, inclusion, and advancement, a key step is to develop a shared vision of desired best practices as a direction for reforms.

Finally, the Academy should consider policy changes related to equity, inclusion, and advancement for nontenure-track faculty. A useful starting point for the Academy based on AAUP recommendations would 


\section{American Journal of Pharmaceutical Education 2021; 85 (3) Article 8428.}

involve reconsideration of policies for description of duties, regular evaluations, compensation, and promotion based on specified duties, appropriate compensation and fringe benefits, timely notice of non-reappointment, enduring conditions necessary to perform assigned professional duties, and inclusion in institutional and departmental governance.

\section{REFERENCES}

1. AAUP. Contingent faculty positions. https://www.aaup.org/ issues/contingency. Accessed March 1, 2021.

2. American Association of Colleges of Pharmacy. Pharmacy Faculty Demographics and Salaries Reports. https:/www.aacp.org/ research/institutional-research/pharmacy-faculty-demographics-andsalaries. Accessed March 1, 2021.

3. Prescott WA. Facilitating advancement of clinical-track pharmacy faculty members. Am J Pharm Educ. 2020;84(5):Article 7910. 4. Smesny AL, Williams JS, Brazeau GA, et al. Barriers to scholarship in dentistry, medicine, nursing, and pharmacy practice faculty. Am J Pharm Educ. 2007;71(5):Article 91.

5. Bosso JA, Hastings JK, Speedie MK, Rodriguez de Bittner M. Recommendations for the successful pursuit of scholarship by pharmacy practice faculty members. Am J Pharm Educ. 2015;79(1): Article 4.

6. Chisholm MA, Spivey C, Martin JR, Wyles C, Ehrman C, Schlesselman LS. A 5-year analysis of peer-reviewed journal article publications of pharmacy practice faculty members. Am J Pharm Educ. 2012;76(7):Article 127.

7. Franks AM. Design and evaluation of a longitudinal faculty development program to advance scholarly writing among pharmacy practice faculty. Am J Pharm Educ. 2018;82(6):Article 6556.
8. El-Ibiary SY, Yam L, Lee KC. Assessment of burnout and associated risk factors among pharmacy practice faculty in the United States. Am J Pharm Educ. 2017;81(4):Article 75.

9. Darbishire P, Isaacs AN, Miller ML. Faculty burnout in pharmacy education. Am J Pharm Educ. 2020;84(7):Article 7925.

10. American Association of University Professors. The status of non-tenure-track faculty. https://www.aaup.org/report/status-nontenure-track-faculty. Accessed March 1, 2021.

11. Kezar A, Maxey D. Change requires discipline. https:// www.aaup.org/article/change-requires-discipline\#.X0UrGMhKjcs. Accessed March 1, 2021.

12. Leveille C. Access to unemployment benefits. https://www. aaup.org/article/access-unemployment-benefits\#.X0UpY8hKjcs. Accessed March 1, 2021.

13. American Association of University Professors. Resisting the increase in contingent appointments. https://www.aaup.org/resistingincrease-contingent-appointments. Accessed March 1, 2021.

14. American Association of University Professors. The inclusion in governance of faculty members holding contingent appointments. https://www.aaup.org/report/inclusion-governance-facultymembers-holding-contingent-appointments. Accessed March 1, 2021.

15. American Association of Colleges of Pharmacy. House of Delegates. Cumulative policies, 1980-2020. https://www.aacp.org/ article/house-delegates. Accessed March 1, 2021.

16. Asbill S, Moultry AM, Policastri A, Sincak CA, Smith LS, Ulbrich TR. Debating the effectiveness and necessity of tenure in pharmacy education. Am J Pharm Educ. 2016;80(6):94.

17. American Association of Colleges of Pharmacy. Strategic plan. https://www.aacp.org/article/strategic-plan. Accessed March 1, 2021. 